\title{
The Effect of Social Media on Customers' Behaviors in E-commerce: Live Streaming Shopping as an Example
}

\author{
Keran $\mathrm{Fu}^{*}$ \\ School of Journalism and Information Communication, Huazhong University of Science and Technology, Wuhan \\ Hubei 430074, China, \\ 2643973879@qq.com
}

\begin{abstract}
With the development of the Internet, social media has affected every aspect of people's life, including shopping. Live-streaming shopping is a very popular e-commerce mode at present. It is favored by many buyers, at the meantime, many businesses benefit from it as well. This paper mainly studies what aspects of live broadcast sales affect consumer behavior, and finally finds that the most obvious impact of live broadcast sales on consumer behavior is to broaden customers' understanding of commodity information. The research results of this paper can provide reference for e-commerce sellers when they develop better marketing plans.
\end{abstract}

Keywords: social media, e-commerce, live-streaming, customers' behaviors

\section{INTRODUCTION}

Today, we are living in the digital age. Whether on the subway or in a restaurant, we can see people using smartphones or laptops to browse social media everywhere. For many people, social media has become a necessity of life, so it also affects people's various behaviors to a large extent. Social media has such a great influence that marketers have begun to fully explore its role and made many achievements.

Social commerce is a new form of e-commerce emerging in the age of social media. It shares many characteristics of social media, allowing consumers to easily obtain all kinds of product information they want, and even communicate with producers online. Two key points of social commerce are derived from social media features, namely, user contribution and social interaction [1]. In this model, sellers and consumers interact very frequently, such as inviting celebrities to endorsements, publishing cryptic social dynamics (people don't realize that this is an advertisement because it appears in the form of popular science or sharing), live-streaming sales, etc., which can invisibly shape the attitude of the audience [2]. Numerous studies have shown the positive impact of social media marketing interactions on consumer purchase intent [3]. However, few studies have shown how these influences are produced, such as which factor in social commerce affects which step of consumer behavior. Specifically speaking, as early as 1968, Engel, Kollat, and Blackwell proposed that A customer's buying behavior typically has five stages: identifying demand, seeking information, evaluating alternatives, making a purchase decision, and taking action after purchase. If the seller can know how to intervene in a certain stage of the consumer's buying behavior and formulate a more precise marketing plan based on this, then the company will have better benefits.

This article will focus on live-streaming sales, a striking example of social commerce, which has brought huge profits to many Chinese e-commerce sellers. The live broadcast allows buyers and sellers to interact directly, which means that neither of the two is passive, which greatly improves the right of both parties to know. For example, buyers can ask for product information they want to know at any time, and sellers can always understand the needs of consumers. The research results on live-streaming sales can be extended to other social media products as they have many similarities.

\section{LITERATURE REVIEW}

In the past, people generally believed that price was the most important reason for consumers' purchasing intentions. However, after the birth of social commerce, the factors that affect people's purchasing behavior have changed. In 2017, Arli, D. studied the impact of four 
features of social media (entertainment, practicality, information, and stimulus) on consumers' attitudes towards brands, and found that entertainment has the greatest impact. An entertaining advertisement can help people escape reality, distract attention, or release emotions [3].

Buyers' attitudes towards brands tend to affect consumers' brand loyalty, recognition, and purchase intentions. When people become followers of a certain brand or product, the price has no decisive influence on their willingness to consume. On the contrary, some emerging elements in social commerce such as likes, comments, visits, etc. become important Influencing factors [4].

\subsection{Live Streaming in Social Commerce}

Live-streaming shopping is a new type of ecommerce model that uses the Internet to achieve human-computer interaction. Many customers obsess about shopping through live broadcasts because it's easy to view products from different angles, ask questions, and communicate in real-time [5]. Although the phenomenon of live broadcast has received much research attention, most of the literature focuses on the benefits of live broadcast for e-commerce. Some researchers have found that shopping in live broadcasts helps to increase customer engagement [5], but which factors have such an impact and how they affect people's purchasing decisions are not yet known.

\subsection{Customers' Behaviors}

Customers' behaviors talked about in this paper can be roughly understood as purchase decisions. Customers make purchase decisions to cope with the imbalance caused by unmet needs and desires. Generally, customers go through five stages of buying behavior: need identification, information search, alternative product evaluation, purchase decision, and post-purchase behavior [6]. Each step is affected by the consumer's emotions, that is, the customer's consumption behavior may not be caused by rigid needs, but emotions, which can be regarded as a standard of customer engagement. The definition of customer engagement has not yet been finalized, it just has been defined differently as a mental state, a behavior, and a mental process. For example, Zheng et al. (2015) consider customer engagement as individually participating and promoting in brand communities on social networks, while Bowden. (2009) and Brodie et al. (2011) said that customer engagement simulates the potential mechanism of forming customer loyalty for new customers of the company and the one of maintaining loyalty for customers who repeatedly purchase service, and it works psychologically.

\subsection{Relationship Marketing}

Relationship marketing is a popular and successful marketing tool nowadays. In this model, the first purpose of marketing is not to grow GMV (gross merchandise volume), but to establish a stable and longterm relationship with customers as possible (Shah, A. M., Zahoor, S. Z., \& Qureshi, I. H. 2019). When customers' recognition and dependence on the brand increase, the brand can export to these stable customers for a long time; on the other hand, establishing this relationship also means that the brand has gained the trust of consumers. Trust is the key element of ecommerce, it brings a good reputation for the brands, be conducive to beautifying the brand image, enhances brand awareness, and thus long-term development. On the contrary, distrust is one of the main reasons for the failure of e-commerce [7].

\section{RESEARCH METHODOLOGY AND HYPOTHESIS}

\subsection{Methodology}

This research did not target a specific live broadcast platform, and all live shopping platforms in China will be the object of this research. It especially considers Taobao.com, JD.com, Sina Weibo, Douyin, and Kuaishou. These are relatively large e-commerce platforms with live shopping services in China. The reasons why the author decides that this research is not aimed at a specific platform are as follows. First of all, the live shopping functions provided by these social ecommerce platforms are similar, like merchandise visualization, feedback posting, etc. Since there is not much difference between them, targeted research is not necessary. Second, there are currently no head live shopping platforms in China. The number of users on these platforms is relatively average, and there are many cross-users. This study focuses on the consumers' behaviors, and it on one platform may be affected by other platforms. To capture this possibility, the author believes that all platforms should be considered as a whole. Last but not least, special situations are also considered. One of them is that there is a crossover between many platforms. For example, Sina Weibo does not have an online mall. As a result, most of the links posted in the Sina Weibo live shopping room are the link of Taobao.com, and the customer need to jump to Taobao.com for the final purchase. Similarly, on the Kuaishou platform, merchants who are not on the white list cannot get the product link in this platform, so when the merchant sells the product in the live shopping room, they post links to other e-commerce platforms.

This research adopts the survey method. The author designed a questionnaire. These questions are divided into surveys on the personal identity information of 
respondents and surveys on live broadcast consumption behavior. The questionnaire was initially designed in English before being translated into Chinese based on the context. The questionnaire was officially released after the researcher invited 5 "experimenters"friends with at least one year of the live shopping experience, to check whether the questionnaire can be understood directly and correctly.

The questionnaire was posted on the website of Wen Juan Xing (https://www.wjx.cn/), one of the largest specialized data collection sites in China. Thanks to the powerful function of data collection and analysis, the distribution of answers can be visually seen in the form of graphs on this website.

\subsection{Hypothesis}

Hypothesis 1: Live-streaming sales lengthen customers' buying decision time

Hypothesis 2: Live-streaming sales widen the range of customers' information searching

Hypothesis 3: Live-streaming sales make customers more likely to compare alternative products.

\section{DATA AND FINDINGS}

In this questionnaire survey, the questionnaire was randomly distributed to respondents in China, the researcher finally received a total of 107 valid answers,

Table1: What kinds of goods would you buy (or consider buying) in live streaming sales? (Multiple choice)

\begin{tabular}{|c|c|c|}
\hline Options & Number of people & Percentage \\
\hline Costumes & 91 & $85.05 \%$ \\
\hline $\begin{array}{c}\text { Cosmetics and self-caring } \\
\text { products }\end{array}$ & 70 & $65.42 \%$ \\
\hline Foods and drinks & 69 & $64.49 \%$ \\
\hline Household supplies & 66 & $61.68 \%$ \\
\hline Others & 0 & $0 \%$ \\
\hline Number of valid answerers & 107 & - \\
\hline
\end{tabular}

There are many types of live streaming sales. According to the content of the live broadcast, live broadcast sales can be divided into knowledge-based live broadcasts and yelling sales. In knowledge-based live sales, in addition to selling products, the anchor would also have a lot of explanatory content, including the explanation of the product itself and the introduction of knowledge in related fields. This type of live studio is very popular in the beauty and apparel fields. In yelling sales, there are no special hosts or contents, just "seckilling"(Commodity prices dropped to a very low level in just a few minutes or even seconds, and consumers quickly snapped up purchases). According to the host of the live broadcast, live broadcast sales can and most of the respondents $(76.63 \%)$ were young people, aged between $20-40.71 .03 \%$ of them were from southern China and $29.97 \%$ of them were from northern China. Among them, two-thirds of the respondents were women and the rest were men.

The questions in this questionnaire were all based on the respondent's experience of consumption in the live broadcast room. Taking into account that there may be respondents who have not had this experience, in the identity authentication question at the beginning, there was a question asking whether the respondent has bought something in the live broadcast room. If he or she answered no, then the researcher expected him or him to answer the next questions in a hypothetical form. Among the 107 valid answerers, 6 answered that they had no such experience. Because these people accounted for a small proportion of the total number $(5.61 \%)$, the researchers decided to include all their hypothetical answers in the study.

As Table1 showed, in the question of what type of merchandise respondents would generally buy in the live broadcast room, the differences in the number of choices given for various merchandise options are very small, accounting for more than $50 \%$, of which clothing merchandise accounts for the largest proportion $(85.05 \%)$. It could be seen from this that the variety of commodities purchased by the public in the live broadcast room is diverse, and there was no specific purchase of a certain kind of commodity.

also be divided into celebrity live broadcasts, Internet celebrity live broadcasts, brands' official live broadcasts, and amateur live broadcasts.

Table 2 illustrated the distribution of people's preference for different kinds of live broadcasts. To the surprise of the researcher, the most popular livestreaming sales were those involving celebrities and the yelling sales. This can be linked to a very popular phenomenon: the star economy. With the upgrade of social networks and the development of the market economy, several new economic models are gaining popularity in the cultural industry market. One of them is the star economy centered on idols (Cai Qi, 2015). The original intention of customers entering the live 
room may not be consuming, but watching celebrities, and the desire to buy is generated during the viewing process. It can be said that celebrities are a means to attract customers into the live room.

Table2: What type of live streaming sales do you prefer to watch? (multiple choice)

\begin{tabular}{|l|l|l|}
\hline Options & Number of people & Percentage \\
\hline $\begin{array}{l}\text { A. With celebrities } \\
\text { (singers, movie stars, idols, etc.) }\end{array}$ & 89 & $83.18 \%$ \\
\hline $\begin{array}{l}\text { A. Yelling sales ( no } \\
\text { special guests or hosts in the } \\
\text { live room, just "seckilling" })\end{array}$ & 85 & $79.44 \%$ \\
\hline $\begin{array}{l}\text { A. Official ones of a } \\
\text { brand With internet }\end{array}$ & 68 & $63.55 \%$ \\
\hline $\begin{array}{l}\text { A. } \\
\text { celebrities (social influencers, } \\
\text { KOLs, etc.) }\end{array}$ & 50 & $46.74 \%$ \\
\hline Others & 0 & $0 \%$ \\
\hline Number of valid answerers & 107 & - \\
\hline
\end{tabular}

To distinguish between consumption in the live broadcast room and traditional e-commerce consumption, the survey asked why respondents would buy things in the live broadcast room instead of on the general e-commerce platform, and the answers can be shown as Table 3. It said that the biggest influencing factor that motivates people to make this choice is the cost-effectiveness of the product. Almost all respondents $(91.59 \%)$ believed that the costeffectiveness of the product there is higher, it can be explained as the lower price and the bonus gifts.

In addition, the entertainment of the live broadcast room was another major factor that attracts consumers. $82.24 \%$ of respondents agreed that they were accidentally attracted by the products being introduced and sold in the live broadcast room. It could be speculated that the live sales bring accidental

Table3: Why would you buy these things in the live streaming sales? (Compared with traditional e-commerce) (Multiple choices)

\begin{tabular}{|c|c|c|}
\hline Options & Number of people & Percentage \\
\hline $\begin{array}{c}\text { A. Buy more discounts in the } \\
\text { live broadcast room (lower } \\
\text { prices, more gifts, etc.) }\end{array}$ & 98 & $91.59 \%$ \\
\hline $\begin{array}{c}\text { I happened to be attracted by } \\
\text { the product being displayed, } \\
\text { though it was interesting and } \\
\text { wanted to try it. }\end{array}$ & 88 & $82.24 \%$ \\
\hline $\begin{array}{c}\text { The products displayed in the } \\
\text { live broadcast room are more } \\
\text { authentic and credible. }\end{array}$ & 74 & $69.16 \%$ \\
\hline I am a fan of this anchor. (star, & & 56 \\
\hline
\end{tabular}




\begin{tabular}{|c|c|c|}
\hline internet celebrity) & & $0 \%$ \\
\hline Others & 0 & - \\
\hline Number of valid answerers & 107 & opportity \\
\hline
\end{tabular}

When asked "what impact does the real-time interaction between the anchor and the barrage have on you?", more than $60 \%$ of people agreed that this allows them to learn more about the detailed information of the product and also made them stay longer in the live broadcast room. About $50 \%$ of people thought that the barrage affected their opinion of the anchor. At the same time, they would carefully refer to the content of the barrage before purchasing the product, and they would end the barrage when they have questions. This could be connected with the previous article. The special function of the live broadcast room made it easier for customers to learn more product information, which increased the purchasing tendency of customers. At the same time, it could also be seen from here that live-streaming sales widen the range of customers' information searching, in two ways, passive and active. The guest saw the host introducing the product in all directions and answering the questions in the barrage, which was passively acquiring new product information. Guests spontaneously sent barrage to communicate with the anchor, which was to take the initiative to obtain product information. Regardless of the method, the product information obtained by the customer was not only fixed and preset but will increase in real-time.

When investigating people's buying speed(multiple choices), almost everyone would immediately place an order in the live room, and less than $50 \%$ of people will withdraw from the live room to compare similar products before deciding whether to place an order in this live room. From here, the researcher speculated that the live broadcast room had shortened the customer's purchase decision process to a certain extent. There were not enough discoveries to confirm whether livestreaming sales make it easier for customers to compare similar products, but it could be seen that the behavior of shopping around is common in live-streaming sales.

\section{CONCLUSION}

There are some limitations to this study. This study did not take into account factors such as age and occupation. Although age was counted in the survey, no distinguishing study was conducted. At the same time, differences in identity can lead to differences in consumer psychology. For example, high-income consumers with more Internet access rights may have different views on social media from ordinary consumers [3].

The results of this research can be used for social commerce sellers to formulate marketing strategies. Live-streaming sales broaden customers' understanding of product information in both active and passive ways, so sellers can use this opportunity to increase the exposure of product advantages in the live broadcast room. At the same time, research shows that livestreaming sales will bring unexpected purchase behavior, so sellers can use various features of the live room, such as barrage and seckilling to stimulate customers' desire to buy at the moment. Last but not least, the phenomenon of the star economy is very worthy of attention. Attracting customers is the first step in the entire marketing process. E-commerce sellers can conduct preference surveys on target sales groups and use this popular situation to attract customers.

\section{REFERENCES}

[1] Kwahk, K.-Y., \& Ge, X. (2012). The Effects of Social Media on E-Commerce: A Perspective of Social Impact Theory. 2012 45th Hawaii International Conference on System Sciences, 1814-1823. https://doi.org/10.1109/HICSS.2012.564

[2] Saima, \& Khan, M. A. (2021). Effect of Social Media Influencer Marketing on Consumers' Purchase Intention and the Mediating Role of Credibility. Journal of Promotion Management, 27(4), $503-$ 523.https://doi.org/10.1080/10496491.2020.18518 47

[3] Arli, D. (2017). Does Social Media Matter? Investigating the Effect of Social Media Features on Consumer Attitudes. Journal of Promotion Management, 23(4), 521-539. https://doi.org/10.1080/10496491.2017.1297974

[4] Clement Addo, P., Fang, J., Asare, A. O., \& Kulbo, N. B. (2021). Customer engagement and purchase intention in live-streaming digital marketing platforms. The Service Industries Journal, 41(1112),

767-786. https://doi.org/10.1080/02642069.2021.1905798

[5] Cai, J., \& Wohn, D. Y. (2019, January 8). Live Streaming Commerce: Uses and Gratifications Approach to Understanding Consumers' Motivations. https://doi.org/10.24251/HICSS.2019.307

[6] Mudie, P., Cottam, A., \& Raeside, R. (2003). An Exploratory Study of Consumption Emotion in Services. The Service Industries Journal, 23(5), 84-106. https://doi.org/10.1080/02642060308565625 
[7] Hajli, M., Hajli, M., \& Khani, F. (2013). Establishing trust in social commerce through social word of mouth. 7th International Conference on E-Commerce in Developing Countries: With
Focus on e-Security, 1-22.

https://doi.org/10.1109/ECDC.2013.6556738 